Geografia e Ordenamento do Território, Revista Eletrónica

Centro de Estudos de Geografia e Ordenamento do Território

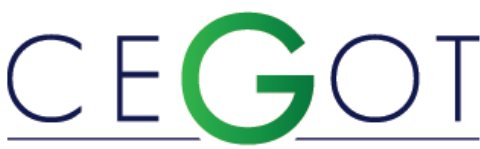

Centro de Estudos de Geografia e Ordenamento do Território http://cegot.org

ISSN: 2182-1267

Jaques Ribeiro, L. M.

Institut für Geologie, Mineralogie und Geophysik

Ruhr-Universität Bochum

luis.jaques@gmail.com

Gonçalves, A. C. R.

Faculdade de Letras da Universidade de Coimbra

CEGOT

anselgoncalves@gmail.com

\title{
Contributo Para o Conhecimento Geológico e Geomorfológico da Área Envolvente do Couto Mineiro da Panasqueira
}

Referência: Jaques Ribeiro, L. M. \& Gonçalves, A. C. R. (2013). Contributo Para o Conhecimento Geológico e Geomorfológico da Área Envolvente do Couto Mineiro da Panasqueira. Revista de Geografia e Ordenamento do Território, n.o 3 (Junho). Centro de Estudos de Geografia e Ordenamento do Território. Pág. 93 a 116.

\section{Resumo}

Neste trabalho, apresenta-se uma súmula dos conhecimentos gerais relativos às características geológicas e geomorfológicas da área em questão, complementados com alguns dados recentes e dentro de uma perspetiva mais atual. A ocorrência das mineralizações de volfrâmio e estanho que caracterizam esta região é, também, aqui 
debatida, procurando-se estabelecer um possível paralelismo com o enquadramento geotectónico onde se inserem.

Palavras-Chave: Minas da Panasqueira, rio Zêzere, Geologia, Geomorfologia, Tectónica, Metamorfismo

\begin{abstract}
This work presents a brief of general acquirements related to geomorphological and geological characteristics of the present area, complemented with some recent data and in a more current perspective. The passage of wolfram and tungsten mineralization which characterizes this zone is, also, discussed here, looking up to determine a possible parallel with the geotectonic integration where they are inserted.
\end{abstract}

Keywords: Panasqueira Mines, Zêzere river, Geology, Geomorphology, Tectonic, Metamorphism.

\title{
1. Introdução
}

No centro de Portugal, mais propriamente na Beira Baixa, surge uma área com características geológicas e geomorfológicas particulares, encaixada entre as serras do Açor, da Estrela e da Gardunha. Na área em causa, situa-se um dos mais importantes jazigos de volfrâmio (W) e de estanho $(S n)$ do Mundo, que é há mais de um século explorado nas Minas da Panasqueira (Thadeu, 1951a; D’Orey, 1967). Trata-se de um jazigo mineral do tipo filoniano, relacionado com a ocorrência de um sistema de "greisen" ${ }^{1}$ associado a uma cúpula granítica em profundidade.

Do ponto de vista geotectónico, a área em questão apresenta-se compartimentada através da ocorrência de importantes acidentes tectónicos NE-SW e ENE-WSW, com

\footnotetext{
1 "Termo anglo-saxónico com raiz no germânico Greisstein (pedra de cinza colorida) que indica uma rocha granular hololeucocrática essencialmente formada por quartzo e mica branca (moscovite), desprovida de feldspato. Pode conter topázio, fluorite, apatite, cassiterite, volframite, minerais de lítio, etc. É interpretado com um granito pneumatolizado, descrito por von Leonhard, em 1823." (in: Carvalho, 2002).
} 
influência direta na sua morfologia (Lourenço, 1996). É nítida a disposição dos relevos em patamares, cujos limites se encontram definidos através de escarpas de falha que, muitas vezes, controlam a própria rede de drenagem.

O bloco montanhoso que se encontra marginado pela Falha de Cebola, situada a norte, e a Falha do Rio Zêzere, mais a sul, apresenta-se abatido relativamente ao restante enquadramento morfológico, essencialmente devido a movimentos tectónicos mais recentes, directamente relacionados com a orogenia Alpina (Cabral, 1995).

\section{Enquadramento Geográfico}

A área envolvente ao Couto Mineiro da Panasqueira localiza-se nos distritos de Castelo Branco e Coimbra, mais propriamente nos limites dos concelhos da Covilhã, Fundão e Pampilhosa da Serra. Com uma área aproximada de $30 \mathrm{~km}^{2}$, situada a sul da serra da Estrela, mais precisamente entre as serras do Açor e da Gardunha, para poente da depressão tectónica conhecida pela designação de "Cova da Beira", esta zona integra o corredor morfo-estrutural denominado de "Serras de Xisto" do Centro de Portugal, que por sua vez, se insere na grande unidade designada por Maciço Hespérico (Ribeiro, 1949a).

A parte sul desta área é atravessada pelo rio Zêzere no sentido ENE-WSW, que constitui o principal receptor de todas as linhas de água da zona envolvente (Figura 1). 
Figura 1 - Enquadramento geográfico da área em destaque neste estudo. (Adaptado da carta militar itinerária de Portugal continental na escala 1/500 000 do Instituto Geográfico do Exército, 1999)

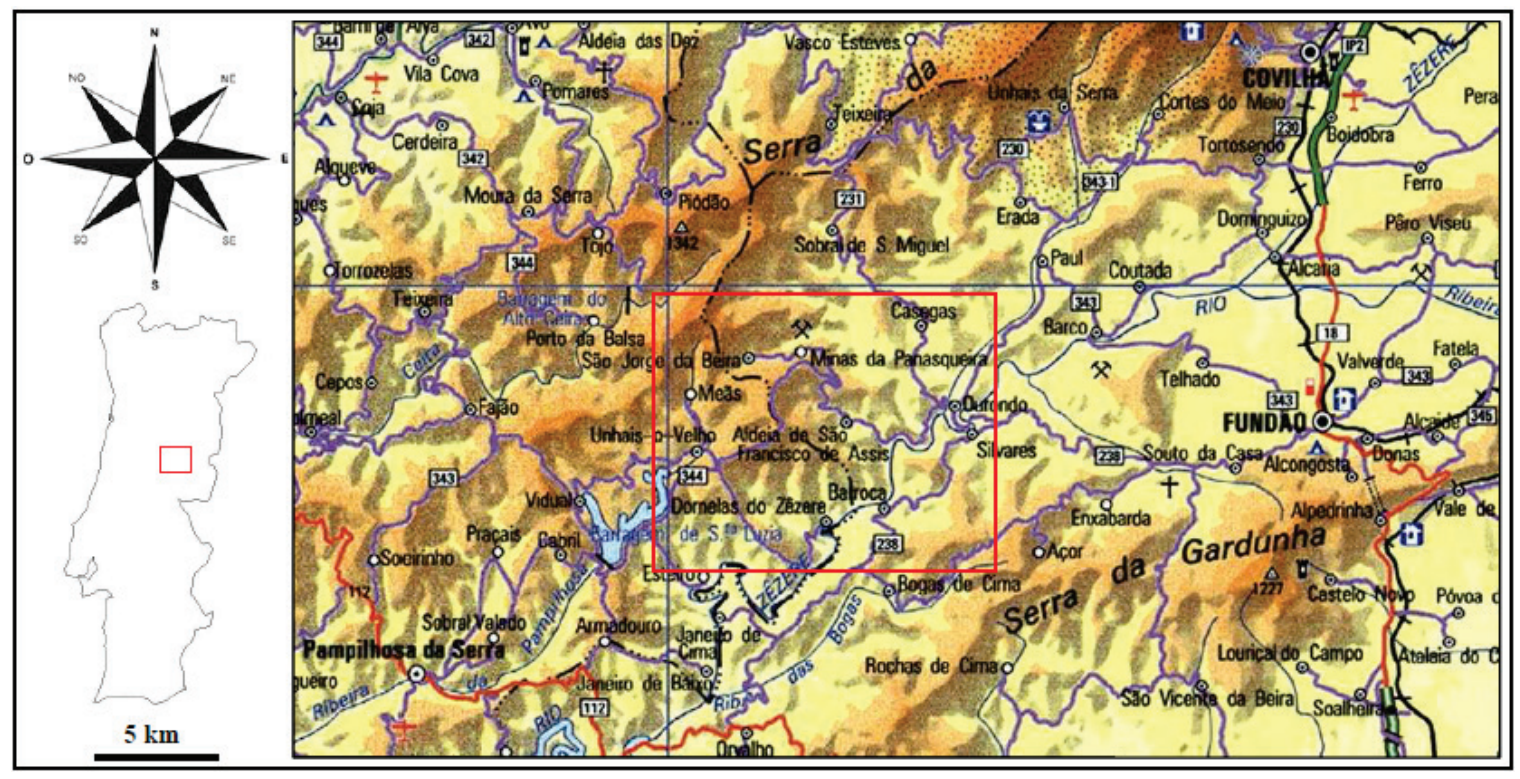

\section{Geologia}

Do ponto de vista geológico, a área envolvente ao Couto Mineiro da Panasqueira insere-se no Maciço Hespérico, mais concretamente em terrenos pertencentes à Zona Centro-Ibérica (ZCl). Estes correspondem a formações metassedimentares, designadas por xistos argilosos das Beiras (Thadeu, 1951a), que integram o "Complexo Xisto Grauváquico" da ZCl, de idade Paleozóica inferior.

Para poente localizam-se as formações quartzíticas já referenciadas, discordantes, pertencentes ao período Ordovícico. Mais para norte e leste da área em estudo, ocorrem ainda litologias graníticas sin e tardi a pós-tectónicas, que constituem distintos maciços bastante individualizados. Assinala-se, ainda, a ocorrência de rochas filonianas de diferentes tipologias e idades (Figura 2). 
Figura 2 - Mapa geológico regional com a área em destaque neste estudo. (Adaptado da Carta Geológica de Portugal na escala 1 / 500000 dos Serviços Geológicos de Portugal, 1992)

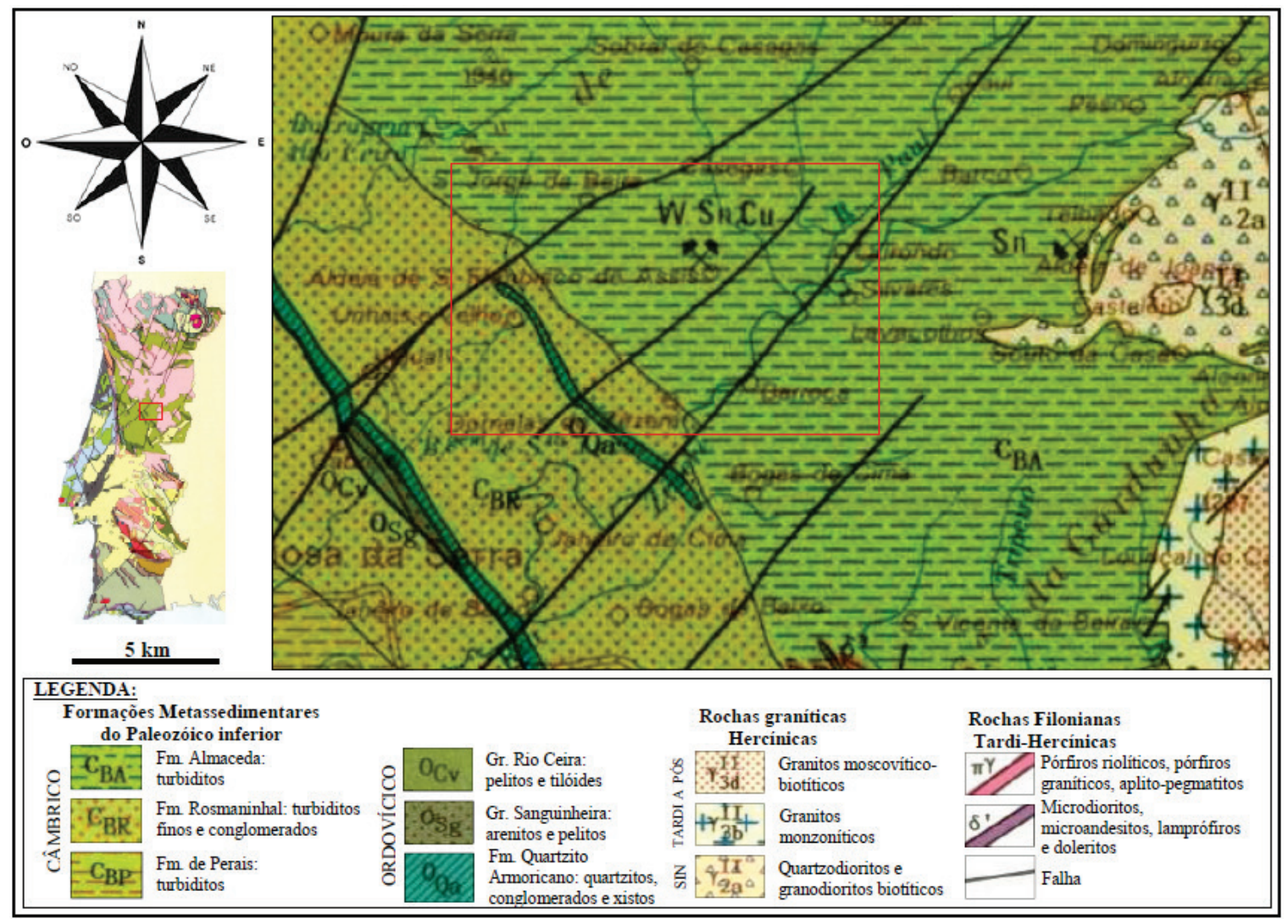

\subsection{Litologias}

\subsubsection{Formações metassedimentares}

De uma maneira geral, as séries metassedimentares inferiores de natureza xistenta, integram regionalmente o "Grupo das Beiras" (Formação $C_{B A}$ ), que corresponde a uma formação de natureza turbidítica e cuja idade é atribuída ao Precâmbrico superior (Sousa, 1985). Para poente, os turbiditos intercalam-se com unidades conglomeráticas $\left(C_{B R}\right)$, passando novamente a turbiditos $\left(C_{B P}\right)$. No entanto, atualmente, estas formações são consideradas do Câmbrico inferior a médio.

Na zona mais próxima do Couto Mineiro da Panasqueira, Thadeu (1951a) refere-se à existência de algumas "diferenciações litológicas" que caracterizam estas formações xistentas. Assim, distingue três variedades, nomeadamente, xistos argilo-gresosos (cor cinzenta), quartzitos xistóides (cor mais clara) e xistos argilosos finos (cor negra). De acordo com Bloot et al., (1953), estas litologias variam entre arenitos lutíticos e 
arenitos. Apresentam-se numa sequência, por vezes, constituindo lentículas alternantes ("xistos listrados").

Mais para poente da área estudada, ocorrem dois importantes afloramentos do Ordovícico, já anteriormente descritos, com uma orientação predominante NW-SE (Figura 2), que constituem séries metassedimentares superiores. Correspondem a relevos importantes dentro da fisiografia que caracteriza a área em estudo, os quais se destacam devido às características das formações geológicas que os constituem. Do ponto de vista geológico, Perdigão (1971) refere que as formações quartzíticas desta região correspondem a estruturas sinclinais que se dispõem sobre as sequências metassedimentares do CXG. A que se situa nas proximidades de Unhais-o-Velho, designada de secundária, desenvolve-se ao longo de $13 \mathrm{~km}$ de comprimento e cerca de $300 \mathrm{~m}$ de largura máxima, apresenta-se pontualmente dobrada e atravessada por falhas (Foto 1). De acordo com este autor, a sequência sedimentar que as constitui inclui bancadas espessas de quartzitos que passam a bancadas delgadas de alternâncias de quartzito-xisto negro do Ordovícico inferior (Formação do Quartzito Armoricano - $\mathrm{O}_{\mathrm{Q} a}$ ). Também se distinguem formações constituídas por arenitos e pelitos, mais recentes, do Ordovícico superior $\left(\mathrm{O}_{\mathrm{sg}}\right.$ e $\left.\mathrm{O}_{\mathrm{cv}}\right)$.

\subsubsection{Rochas graníticas}

Diversas litologias de carácter ácido ocorrem para nascente da área em estudo, nomeadamente, rochas graníticas Hercínicas (Figura 2). Distinguem-se granitos sintectónicos, constituídos por quartzodioritos e granodioritos biotíticos $\left(\gamma^{\prime \prime}{ }_{\mathrm{a}}\right)$, na zona do Fundão. Mais para sul ocorrem granitos tardi a pós-tectónicos, constituídos por granitos monzoníticos porfiróides $\left(\gamma^{\prime \prime}{ }_{3 \mathrm{~b}}\right)$ e granitos moscovítico-biotíticos $\left(\gamma^{\prime \prime}{ }_{3 \mathrm{~d}}\right)$, que já integram a Serra da Gardunha. De acordo com Ferreira et al. (1987), os últimos constituem uma série intrusiva na anterior, mais diferenciada.

$\mathrm{Na}$ área do Couto Mineiro da Panasqueira foi posta a descoberto em profundidade uma rocha granítica de duas micas que, de acordo com Ferreira et al. (1987), se insere no grupo dos granitos pós-tectónicos. A sua idade obtida através de K-Ar indica 289$293 \pm 10$ Ma (Clark, 1970). 


\subsubsection{Rochas filonianas}

As formações xistentas da região das Beiras encontram-se atravessadas por numerosas ocorrências de rochas filonianas de carácter básico. Thadeu (1949) distingue filões ante-Hercínicos, com orientação predominante segundo N-S, relacionados com movimentos "Caledónicos" e filões Hercínicos a pós-Hercínicos, orientados segundo EW (Figura 3).

Na área definida neste estudo, são relativamente abundantes os filões de composição básica que atravessam as formações de natureza xistenta. Apresentam-se em geral muito verticalizados, com uma possança variável entre 0.5 e 3.0 metros, orientam-se segundo N-S e, menos frequentemente NW-SE e NE-SW (Thadeu, 1951a; D'Orey, 1967).

Quanto à origem dos filões de rochas básicas, Thadeu (1951a) relaciona-os com a fase de descompressão que decorreu no final da orogenia Caledónica. Também são assinaladas ocorrências de rochas filonianas consideradas tardi-Hercínicas, as quais definem dois grupos principais, constituídos por microdioritos, microandesitos, lamprófiros e doleritos $\left(\delta^{\prime}\right)$ e pórfiros riolíticos, pórfiros graníticos e aplito-pegmatitos $\left(\pi^{\gamma}\right)$, relacionadas com eventos magmáticos que decorreram durante o Mesozóico. Estas litologias situam-se mais para sul e assumem uma orientação predominante segundo NW-SE. 
Figura 3 - Enquadramento geológico e geomorfológico da área em análise. Os dados inseridos foram obtidos a partir de trabalhos de campo efetuados pela empresa Sojitz Beralt Tin \& Wolfram, Portugal, S. A. e para o Projecto e-Ecorisk (Ávila, 2008). Os contactos litológicos são baseados na Carta Geológica de Portugal na escala 1:500 000 (1992). A base fotográfica corresponde à imagem obtida a partir do Google Earth.

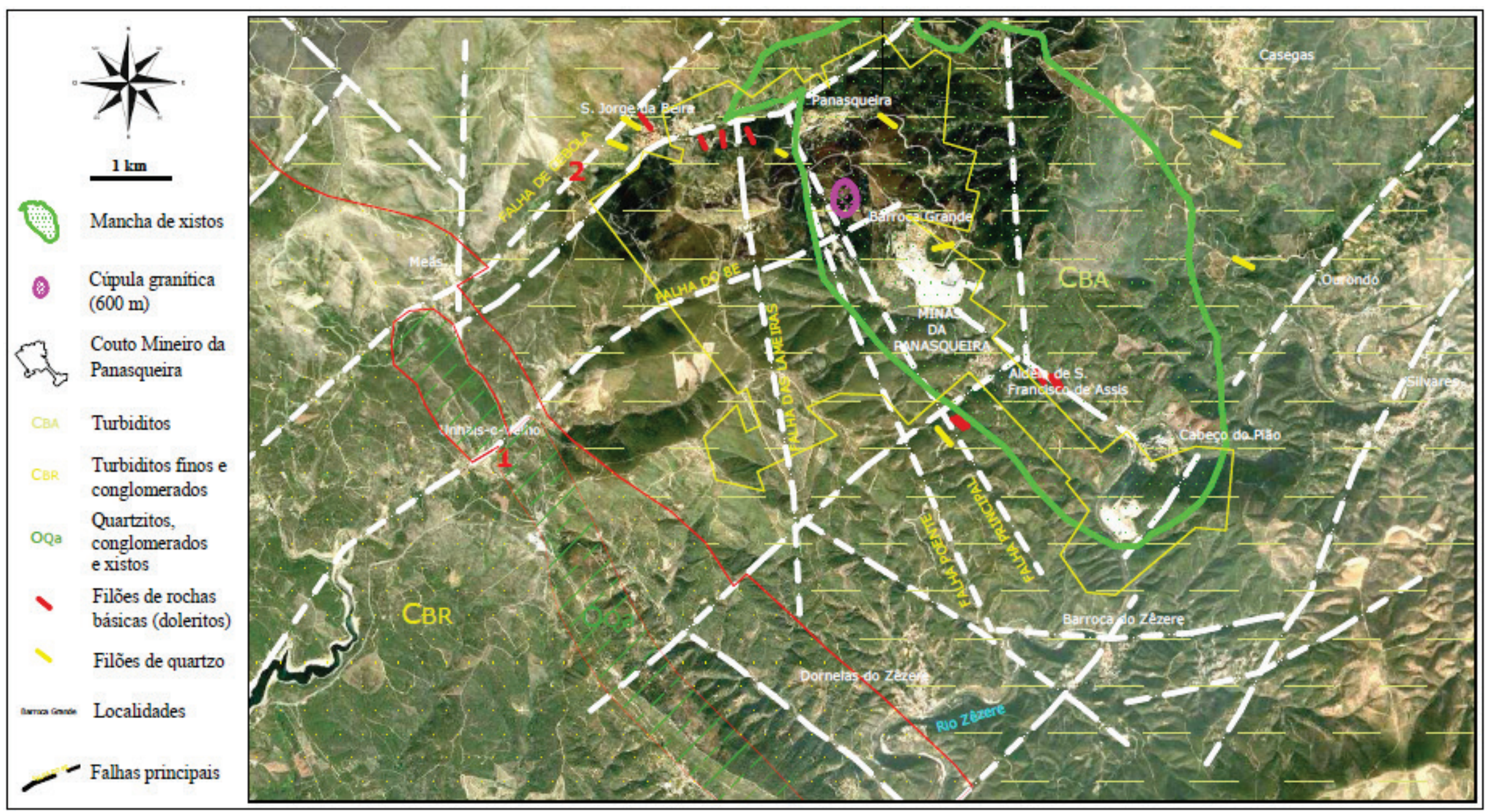




\subsection{Tectónica e metamorfismo}

Toda a região considerada foi afetada por metamorfismo orogénico, tendo resultado na atual configuração apresentada pelas formações metassedimentares do CXG. De acordo com Teixeira (1981), são definidos dois períodos principais de deformação. O primeiro é considerado ante-Hercínico e levou à formação de dobras largas com eixos orientados segundo NNE a ENE. Quanto ao episódio posterior, de idade Hercínica, resultou no desenvolvimento de clivagem xistenta de plano axial, sub-vertical e com orientação predominante segundo NW-SE. Relativamente à área do Couto Mineiro da Panasqueira, Reis (1971) refere que os xistos argilosos apresentam dobramentos, cujos eixos se orientam segundo a direcção NE-SW, bem distinta da xistosidade (Thadeu, 1949). No caso da área em estudo, a orientação definida pelas camadas estratigráficas varia de EW a NE-SW, com uma inclinação de 40-50 para SE. Thadeu (1951a) e Bloot et al., (1953) consideram que estas formações terão sido afetadas por movimentos anteriores, atribuídos à orogenia Caledónica.

Antão (2001) refere que a área em estudo sofreu dois tipos de metamorfismo. O primeiro do tipo regional e de baixo grau, da fácies dos xistos verdes, possivelmente contemporâneo da segunda fase de deformação compressiva Hercínica $\left(F_{2}\right)$, que terá decorrido entre 360 e 330 Ma (Dias et al., 1998). Já anteriormente Teixeira (1981) definiu para estas litologias um grau de metamorfismo baixo, não ultrapassando a fácies dos xistos verdes (sericite-clorite).

Ainda de acordo com Antão (2001), ocorreu um segundo tipo de metamorfismo de contacto, originado pela intrusão dos granitos Hercínicos mais recentes. Este último metamorfismo provocou nos leitos mais argilosos o aparecimento de xistos mosqueados, sendo um indicador de um corpo ígneo intrusivo em profundidade (Figuras 3 e 4). O mesmo fora anteriormente referenciado nos trabalhos desenvolvidos por Thadeu (1949, 1951a, 1951b, 1971 e 1973). 


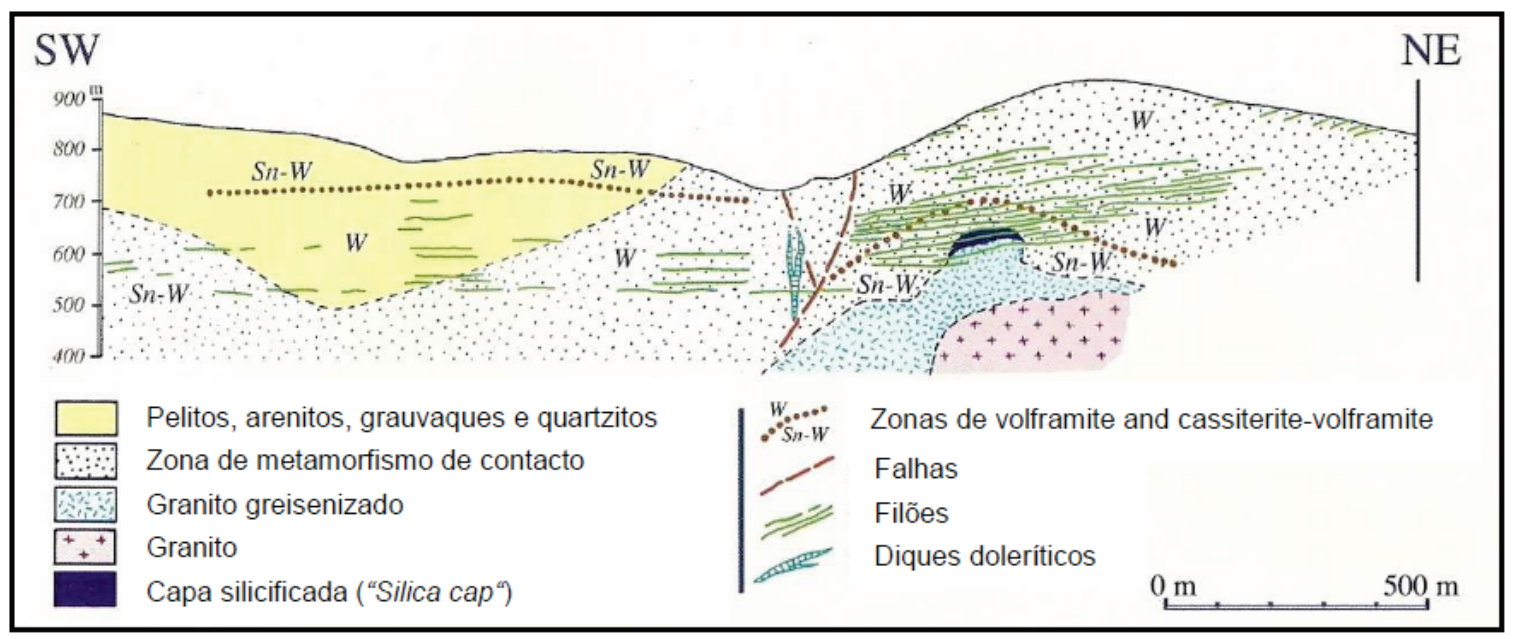

O carácter mosqueado que foi adquirido pelas formações xistentas derivou do contacto com uma cúpula granítica situada em profundidade, a qual produziu localmente metamorfismo de contacto, cujos nódulos correspondem a biotite, clorite, quiastolite e cordierite (Figura 4). Nas formações xistentas mais gresosas, este efeito revela-se através do seu aspeto sacaróide e cor escura. Segundo Thadeu (1951a), a orla metamórfica desenvolve-se ao longo de $0.5 \mathrm{~km}$, principalmente na sua parte mais oriental, com uma forma elíptica característica, cujo eixo principal se orienta segundo NW-SE. No entanto, trabalhos desenvolvidos mais recentemente levaram à definição de uma orla de xistos mosqueados ainda mais ampla (Ávila et al., 2008).

A região das Beiras foi afetada por episódios de fracturação que se desenvolveram durante um período designado por Tardi-Hercínico, entre 310 e 270 Ma (Arthaud \& Matte, 1975). No entanto, Marques et al. (2002) admitem um limite mais antigo para o início dos episódios de fracturação situado em $312 \mathrm{Ma}$, com base em datações de K-Ar efetuadas em moscovites. De facto, constata-se uma compartimentação do soco rochoso Hercínico através de sistemas de falhas conjugadas, orientadas segundo N-S, NNE-SSW e ENE-WSW (Thadeu, 1949; Teixeira, 1981).

Relativamente à Cordilheira Central, Cabral (1995) admite que esta é limitada a sul por um conjunto de falhas de orientação média NE-SW e ENE-WSW. A atuação Alpina no soco Pré-Câmbrico impôs que as estruturas Tardi-Hercínicas do tipo "strike-slip" com orientação ENE-WSW e NE-SW, fossem reativadas através de movimentações esquerdas como falhas inversas durante o Cretácico e, no caso da área em estudo, com vergência para SE (Ribeiro, 1979, 1990; Cabral, 1995). Cabral (1989) assinala o movimento 
esquerdo que as caracteriza, considerando, no entanto, deslocamentos verticais variáveis para estas estruturas. Ribeiro (1988) e Daveau et al., (1986) consideram que o principal impulso de levantamento da Cordilheira Central terá decorrido há cerca de 10 Ma, durante a compressão Alpina, prolongando-se entre o Miocénico superior e o Quaternário.

No caso concreto da área em estudo, é possível verificar através de uma análise interpretativa de fotografia aérea (Figura 3), que a mesma se encontra localmente afectada por estruturas frágeis de enorme relevo, as quais se encontram impressas em alguns dos principais aspectos geomorfológicos e geológicos que a caracterizam. Já anteriormente Thadeu (1951a e b) referiu a existência de dois sistemas principais de falhas no Couto Mineiro da Panasqueira, um com direcção N-S e outro ENE-WSW, que se encontram bem definidos através de uma série de acidentes de desenvolvimento subparalelo, os quais se encontram materializados através da ocorrência de linhas de água encaixadas, nas vertentes das zonas mais montanhosas. Ambos os sistemas são, segundo o mesmo autor, posteriores à génese dos filões mineralizados em volframite e cassiterite.

No sistema N-S, incluem-se algumas falhas importantes, nomeadamente, Falha Principal, Falha Poente, Falha da Fonte das Lameiras e Falha do Vale das Freiras. Trata-se de estruturas sub-paralelas e com orientação predominante $\mathrm{N} 12^{\circ} \mathrm{W}$, cuja caixa de falha com possança métrica pode apresentar material brechificado e/ou esmagado, bem como preenchimento de argila (Figura 3).

Quanto ao segundo sistema, referem-se a Falha de Cebola e Falha dos 8 Este. Ambas ocorrem a norte da área em estudo, delimitando dois blocos importantes, com diferentes altimetrias. Thadeu $(1949,1951 b)$ descreve relativamente à primeira estrutura, uma caixa larga com a presença de fragmentos de xisto, bem como a ocorrência irregular de mineralização de blenda e galena com ganga quartzocarbonatada associada.

Através da análise da Figura 3, é possível notar o movimento esquerdo atribuído a estas estruturas, o qual é característico do sistema de falhas N $80^{\circ} \mathrm{E}$ (Marques et al., 2002). Assim, ao longo do seu percurso a Falha de Cebola atravessa a parte norte da área em estudo, junto à povoação de S. Jorge da Beira, continuando para SW, onde corta as 
cristas quartzíticas situadas mais a poente. Ávila et al. (2008) referem um deslocamento horizontal de cerca de 95 metros para as formações xistentas que se encontram afectadas pela Falha de Cebola.

Da mesma forma, junto às formações quartzíticas que ocorrem a poente da área em estudo, é possível determinar o rejeito horizontal de ambos os blocos separados, neste caso, associados à Falha dos 8 Este. De acordo com Perdigão (1971), esta apresenta uma componente de movimento esquerda, transversal, cujo deslocamento atinge os 660 metros.

Mais para sul da área em estudo ocorre outra estrutura relacionada com o sistema frágil NE-SW, que condiciona o vale sinuoso do Rio Zêzere, e com a mesma orientação predominante, a qual é visível através do contacto entre as diferentes formações xistentas.

De uma forma geral, Thadeu (1951b) define esta região como sendo constituída tipicamente por "grabens" e "horsts". Esta descrição é seguida por Daveau et al., (1986), chegando a admitir que os relevos resultantes das acções tectónicas (entalhe do vale do rio Zêzere e as superfícies elevadas envolventes) se mantiveram funcionais até à actualidade.

\subsection{Jazigo de W-Sn da Panasqueira}

Dentro da área definida neste estudo, situa-se o Couto Mineiro da Panasqueira (Figura 3). Trata-se de um importante jazigo de W-Sn, o qual já foi amplamente caracterizado através dos trabalhos desenvolvidos anteriormente por diversos autores, quer sob o ponto de vista geológico (Thadeu, 1951a; D’Orey, 1967; Kelly \& Rye, 1979) e estrutural (Marignac, 1973; Foxford et al., 2000), quer das fases fluidas mineralizantes (Bussink, 1984; Polya, 1987; Noronha et al., 1992; Lourenço, 2002, 2006).

Quanto ao jazigo da Panasqueira propriamente dito, este define uma zona mineralizada com uma área com cerca de 2500 metros de comprimento e largura variável entre 400 e 2200 metros (Cavey \& Gunning, 2006). É constituído por um vasto campo filoniano, o qual se notabiliza pelas dimensões dos filões de quartzo mineralizados em volframite, cassiterite e sulfuretos, com possanças que podem ultrapassar 1 metro, bem como, pela 
sua riqueza e paragénese mineral. Relativamente a esta última, foram definidos quatro estádios distintos para a deposição da mineralização nos filões (Kelly \& Rye, 1979):

1) Estádio de óxidos-silicatos (quartzo, volframite e cassiterite)

2) Estádio principal de sulfuretos (pirite, arsenopirite, pirrotite, esfalerite, calcopirite)

3) Estádio de alteração da pirrotite (marcassite, siderite, galena, sulfossais de $\mathrm{Pb}$-Si$\mathrm{Ag})$

4) Estádio dos carbonatos tardios (dolomite, calcite)

Com base no conhecimento geológico do local, incluindo o pendor e direcção dos filões, bem como, os principais acidentes tectónicos, Thadeu (1951a) propôs uma divisão em diversas zonas mineralizadas dentro do Couto Mineiro da Panasqueira. Os principais trabalhos de lavra desenvolveram-se entre Vale de Ermida e Panasqueira (mais a norte) e Cabeço do Pião (mais a sul), entre outros. No entanto, a Barroca Grande (onde decorrem atualmente todos os trabalhos mineiros), constitui a principal zona mineralizada (Figura 3).

A mineralização filoniana de W-Sn apresenta-se acompanhada por importantes ações metassomáticas, cujo expoente máximo corresponde à "greisenização" da rocha granítica que se encontra subjacente aos xistos encaixantes. De acordo com Bussink (1984), esta rocha corresponde a um granito de duas micas, cuja cúpula regista transformações mineralógicas importantes e que resultaram na formação de um "greisen" constituído por moscovite e quartzo (Figura 4).

De acordo com Ribeiro \& Pereira (1981), as mineralizações de W-Sn da Panasqueira estão inseridas num grupo maior, considerado tardi a pós- $F_{3}$, tendo a génese dos filões sido controlada por um campo de tensões local, ligado a um mecanismo de instalação de granitóides Hercínicos tardi a pós-tectónicos. Relativamente a este aspeto, Lourenço (2006) conclui que o granito da Barroca Grande apresenta características semelhantes ao granito da Argemela. Ao mesmo tempo, estes formam um alinhamento W-E coincidente com um outro relativo a mineralizações de Sn. Assim, segundo o mesmo autor, o granito da Panasqueira terá derivado do granito da Serra da Estrela (biotítico e tardi a pós- $\left.F_{3}\right)$, da mesma forma que o granito de Argemela. 


\section{Enquadramento Geomorfológico}

A área analisada insere-se numa região montanhosa que apresenta altitudes que variam entre 325 metros, junto ao rio Zêzere, e 1418 metros, na serra de Cebola, na qual predominam formações metamorfizadas que pertencem à mancha do CXG das Beiras (Figura 5). Segundo Lourenço (1996), "do ponto de vista meramente estrutural, é patente o nítido domínio da orogénese hercínica, que imprimiu uma orientação geral às camadas situadas próximo dos $\mathrm{N}^{\circ} \mathrm{W}$, no Complexo Xisto-Grauváquico".

Figura 5 - Mapa geomorfológico regional com indicação da área definida neste estudo. (Adaptado a partir da Carta Geomorfológica de Portugal na escala 1 / 50000 do Centro de Estudos Geográficos, 1981).

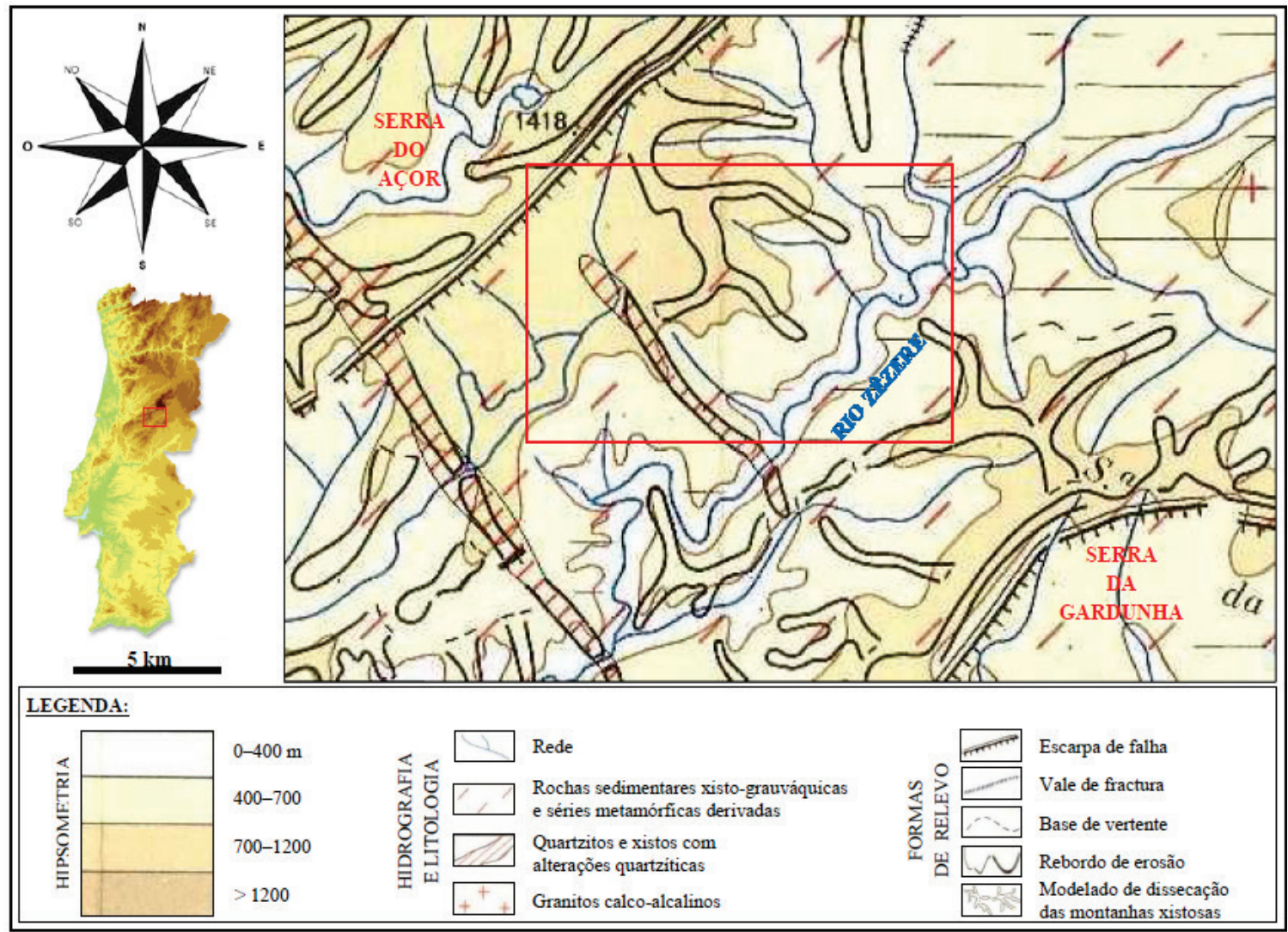

Posteriormente ao CXG, surgem as formações de quartzitos e xistos de idade Ordovícica, que se encontram dobradas pela mesma orogenia e são atravessadas por falhas bem desenvolvidas. Devido à sua dureza, estas formações quartzíticas destacam-se da topografia geral ${ }^{2}$ com uma direcção NW-SE predominante, sendo bem observáveis a poente do Couto Mineiro da Panasqueira (Foto 1).

\footnotetext{
${ }^{2}$ Rebelo (1975) observou tal dureza dos quartzitos nas serras de Valongo, sendo esta responsável pela existência de cristas de corpo alongado e que se destacam da topografia circundante, que neste caso é constituída por xistos.
} 


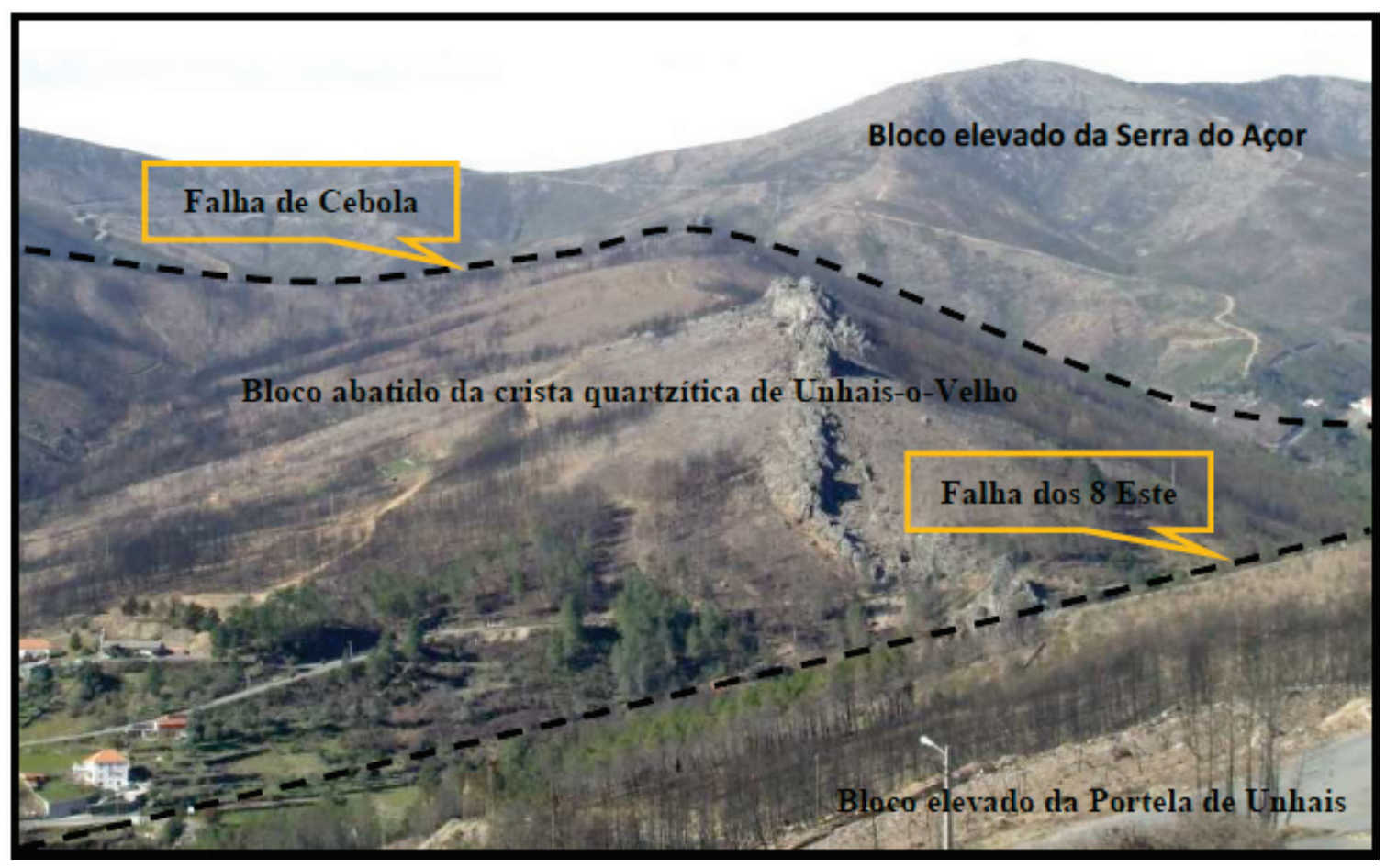

A importância da tectónica está bem presente através da movimentação de blocos que hoje constituem serras individualizadas e desniveladas entre si. Apesar da constatação dos movimentos tectónicos ao longo de estruturas ENE-WSW, em muitos desses acidentes torna-se difícil marcar com exatidão os deslocamentos verificados. Lourenço (1996) sugere que seja considerada a ocorrência das cristas quartzíticas (Vidual e Unhais-o-Velho) situadas a poente da área em estudo, para demonstrar alguns aspectos dessa movimentação. De facto, toda a ação da tectónica frágil associada à movimentação de blocos que ela comporta, encontra nos quartzitos o material rochoso ideal para conservar a expressão desses movimentos, devido ao grau de dureza que os caracteriza. Na realidade, a análise das cristas quartzíticas permite depreender com alguma segurança as movimentações sofridas porque conservam o resultado dessas ações, estando-se neste caso perante deformações da superfície culminante da montanha, ela mesma derivada do arrasamento Eocénico (Daveau et al., 1986).

A crista que é aqui designada de secundária, corresponde ao sector de Portela de Unhais, ligeiramente soerguida em relação ao bloco de Selada da Porta e Machialinho. Apenas localmente, nos Penedos de Unhais ganha relativa importância, pois as maiores altitudes registam-se na serra do Chiqueiro que, por ser constituída por xisto, confirma a importância da movimentação tectónica para o soerguimento das "Serras de Xisto". Esta 
crista permite evidenciar a importância atribuída ao rejeito lateral da falha de Cebola que a limita a Norte, interrompendo mesmo o seguimento deste afloramento quartzítico. Assim, os afloramentos quartzíticos além de testemunharem a movimentação relativa dos blocos que os integram, fornecem também elementos de comparação com as altitudes mais elevadas encontradas nos xistos, e que só podem ser interpretados como resultantes da atuação da tectónica.

Ao visualizar-se o perfil longitudinal das duas cristas (Vidual e Unhais-o-Velho), pode verificar-se até que ponto a rede de falhas impõe a segmentação dos blocos e os soergue de forma distinta (Foto 1). No entanto, é a falha de Cebola (de importância regional) que soergue de forma vigorosa a serra do Vidual para altitudes acima dos 1.100 metros (1.108 m, v. g. de Batouco) e que se dirige para ENE, desenvolvendo-se de forma quase rectilínea, seguindo o vale da ribeira de Cebola, estando essa importância muito bem marcada na divisa do concelho da Covilhã com o da Pampilhosa da Serra, mais propriamente na Portela de S. Jorge. Nesse local, junto à caixa de falha situada a 895 metros de altitude, surge um depósito que se pode definir como crionival, sendo constituído por pequenas patelas de xisto, isto é, por pequenas laminas desse material e com fraca matriz argilosa (Foto 2).

Foto 2 - Vista em pormenor da falha de Cebola no sentido NE-SW, onde se localiza o depósito crionival a ela associado. Foto tirada na estrada que liga S. Jorge da Beira à Portela de S. Jorge (Gonçalves, 2007)

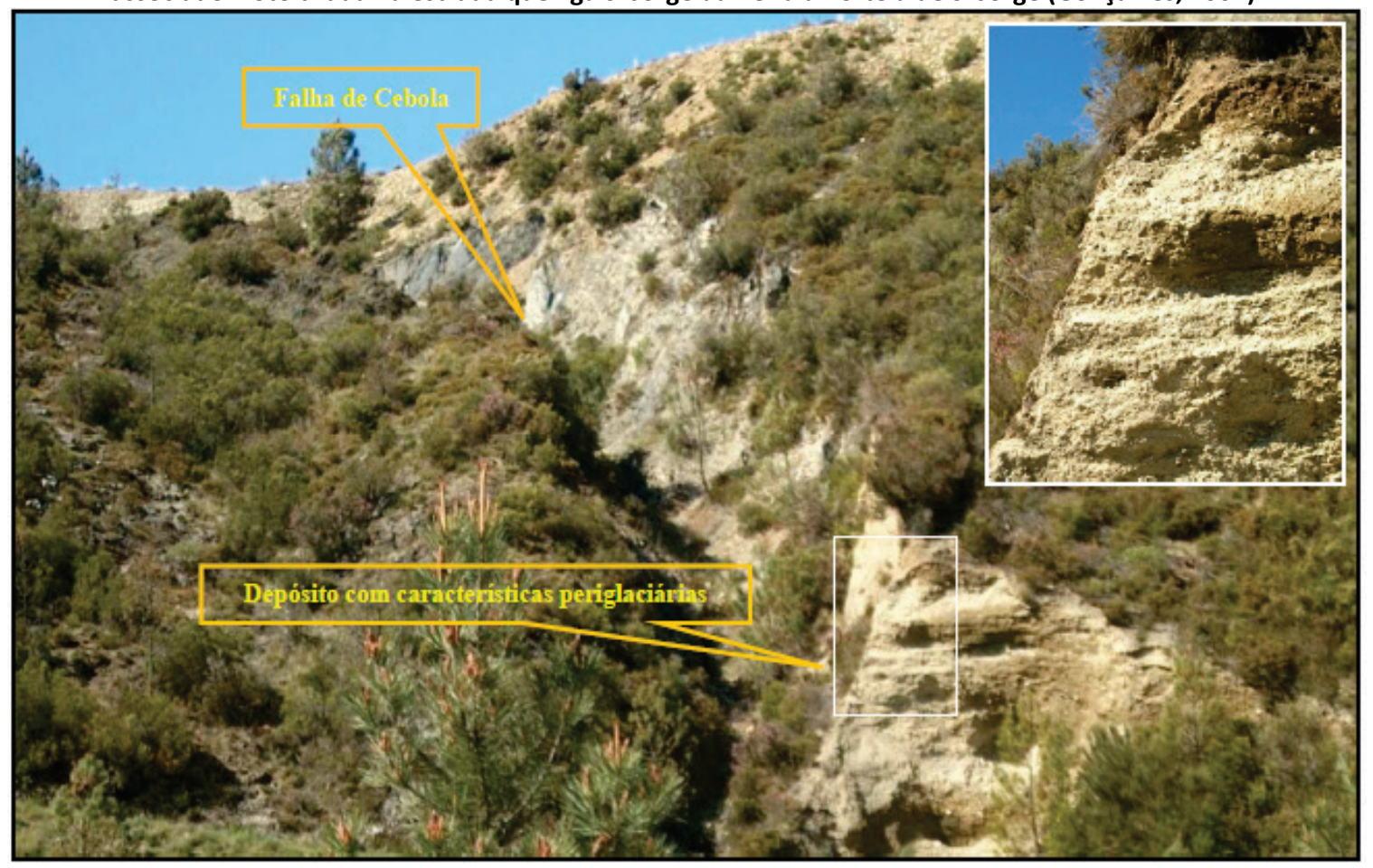


Localmente denominam este tipo de patelas como "lâminas" de xisto, cuja disposição muitas vezes se assemelha às lâminas acamadas umas em cima das outras. Esta denominação genérica permite agrupar um leque variado de depósitos, em cuja génese terão predominado processos do tipo crionival associados ao frio, aglutinando os depósitos normalmente mencionados na literatura francesa como "dépôts de pente (de versant) stratifiés", os quais não incluem os "éboulis ordonnés (stratifiés)" por estes serem depósitos cujo declive máximo ( $\alpha$ máx. $\geq 30^{\circ}$ ) implica um controlo direto da gravidade (queda de pedras) (Coutard et al., 1987 in Lourenço 1996). Perante esta definição, o depósito apresenta-se como sendo estratificado de vertente e por apresentar uma estruturação específica, alternando de forma mais ou menos regular os leitos de materiais detríticos ordenados que o compõem. Normalmente, estes leitos são constituídos por fragmentos grosseiros, envolvidos numa matriz argilosa fina, em regra pouco abundante, os quais terão resultado do rebentamento do substrato que forma a vertente por acção do gelo (crioclastia).

$\mathrm{Na}$ área caracterizada, a hidrografia encontra-se adaptada a uma apertada rede de fracturas, dado que os rios e ribeiras se organizaram preferencialmente utilizando curtos tramos rectilíneos e explorando alinhamentos que, posteriormente, infletiram de forma repentina, obrigando os rios a meandrizar. Embora com uma evolução confinada à rede de fracturas, muitos deles encaixaram-se profundamente, através de um entalhe progressivo, sendo possível evidenciar como exemplo desse encaixe, o próprio rio Zêzere (Figura 6). 
Figura 6 - A meandrização do rio Zêzere entre o Cabeço do Pião e Janeiro de Cima

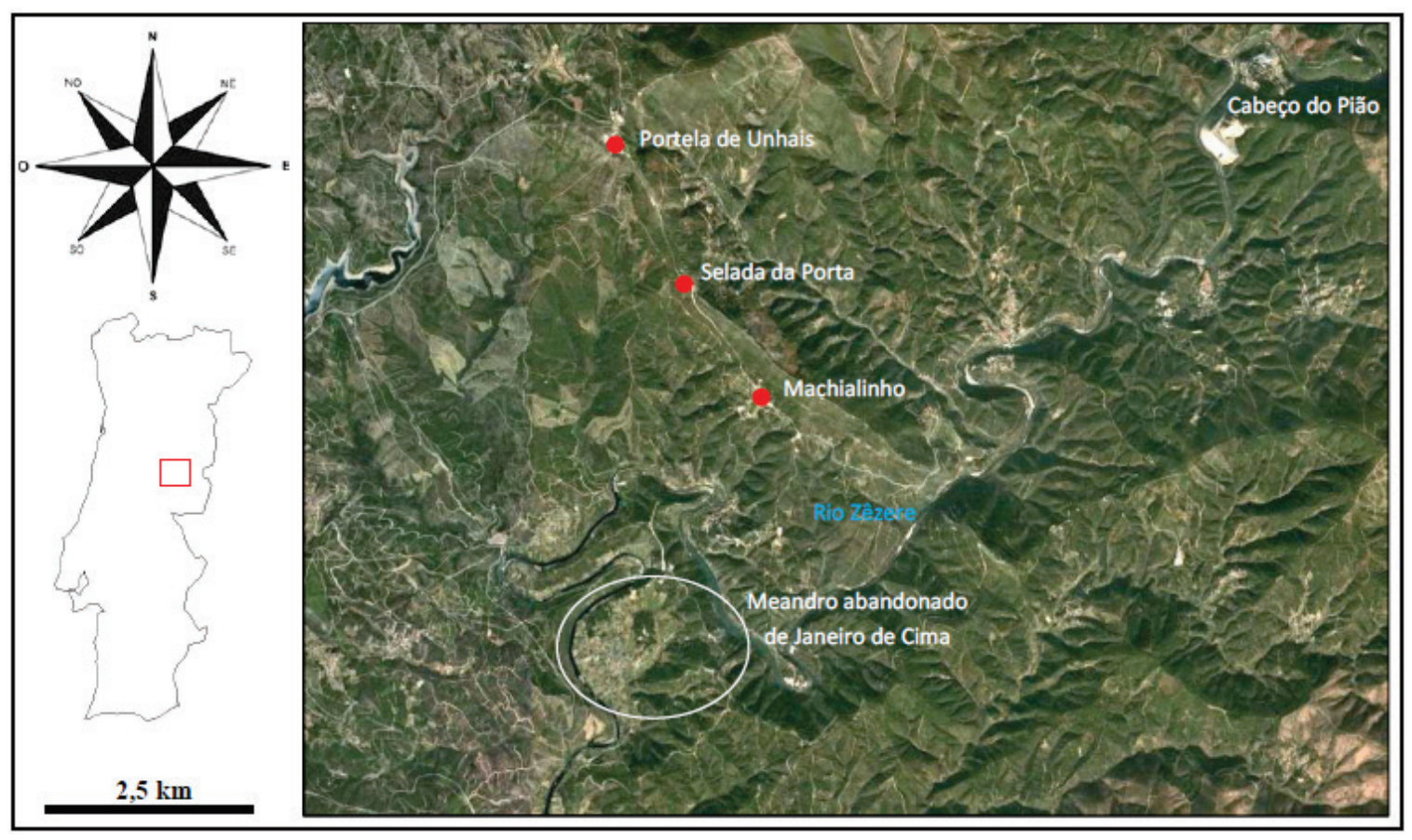

A geometria dos vales esculpidos por estes rios e ribeiras indica de uma forma geral a presença de cimos arredondados, terminando em depressões bastante estreitas e, nalguns casos, sugerindo um encaixe rápido e recente.

\section{Discussão}

Perante a necessidade de se proceder a uma análise conjunta dos elementos geológicos e geomorfológicos da área que é aqui considerada, efetuou-se uma avaliação multidisciplinar tendo em vista disponibilizar uma perspetiva ainda mais atualizada no que concerne aos principais aspetos da geologia e do relevo desta região.

Assim, é possível afirmar com alguma segurança que as formas de relevo atuais devemse fundamentalmente à atuação da orogenia Alpina, que desta forma continua a manifestar-se devido a ações da neotectónica, através da eventual reativação de fraturas anteriores, Hercínicas. É evidente que a tectónica vigente imprime também alguma rigidez à rede hidrográfica em determinados sectores, tais como, o rio Zêzere ao longo de todo o seu traçado, ribeira de Unhais desde Meãs até Unhais-o-Velho, ribeira da Póvoa da Raposeira e ribeira do Bodelhão. 
À medida que os quartzitos se tornam menos possantes e as fracturas transversais são mais importantes, os rios atravessam as cristas por intermédio de vales relativamente largos adaptados à estrutura. Pode-se referir um caso particular deste tipo de adaptação nas proximidades dos Penedos de Unhais. Com efeito, este afloramento encontra-se abatido entre a falha de Cebola, a norte, e a falha de Unhais (prolongamento da falha dos 8 Este?) paralela à anterior, a sul.

Por outro lado, um conhecimento mais aprofundado acerca das características geológicas e geomorfológicas da região envolvente ao Couto Mineiro da Panasqueira assume um papel fundamental, não só na definição do próprio jazigo mineral, mas também para a sustentação do seu próprio modelo genético, visando mesmo servir de base numa perspetiva futura para a procura de novas áreas mineralizadas. Deste modo, a falha de Cebola situada mais a norte, poderá constituir um limite tectónico importante para a parte do jazigo que é actualmente conhecida. No entanto, a possibilidade de um prolongamento deste para o bloco localizado para norte da referida falha, não deverá ser totalmente colocada de parte, mesmo sabendo-se que este se encontrará provavelmente num nível estrutural superior, mais elevado ou, mesmo, que tenha já sido erodido. Da mesma forma, a falha do Rio Zêzere com a mesma direcção constituirá um limite a sul, o qual demarca os filões mineralizados da zona do Cabeço do Pião.

Também, a definição da mancha de xistos mosqueados diretamente associados com a ocorrência em profundidade da cúpula granítica da Panasqueira se prolonga nesta mesma direção, o que constitui um aspeto relevante que apoia a hipótese aqui considerada. De acordo com o modelo genético definido para o jazigo, o facto de os próprios filões mineralizados se encontrarem associados a uma apófise granítica pouco profunda, será por si só um fator condicionante para a possível ocorrência de outras zonas mineralizadas semelhantes. No caso da área situada mais a poente, esta estará teoricamente mais afastada das grandes massas rochosas associadas com os granitos da Serra da Estrela e do Fundão, pelo que, neste caso, a espessura de uma sequência metassedimentar de cobertura será aí mais significativa. Assim, poderá ficar desta forma mais limitada a existência de outras intrusões graníticas sob os xistos do CXG.

Uma hipótese teoricamente mais plausível para o reconhecimento de outras zonas mineralizadas semelhantes às da Panasqueira poderá corresponder a toda a zona 
situada mais a norte e a nascente da área, incluindo a que se insere dentro do bloco abatido entre as estruturas frágeis NE-SW assinaladas.

Por outro lado, a ocorrência conhecida de filões de quartzo ricos em Sn na zona de Argemela (Fundão), que ocorrem para sul do alinhamento da Falha do rio Zêzere, poderá perspetivar uma outra possibilidade de novos campos filonianos fora do bloco abatido.

\section{Referências bibliográficas}

Antão, A.M. (2001). “Os Recursos Minerais na Beira Baixa”. Geonovas 15: 45-59.

Arthaud, F. \& Matte, P. (1975). "Les decrochements tardi-hercyniens du sud-ouest de l'Europe. Geometrie et essai de reconstitution des conditions de la deformation". Tectonophysics, 25: 139-171.

Ávila, P.; Ferreira da Silva, E.; Salgueiro, A. \& Farinha, J. A. (2008). "Geochemistry and Mineralogy of Mill Tailings Impoundments from the Panasqueira Mine (Portugal): Implications for the Surrounding Environment". Mine Water Environ., 27: 210-224.

Bloot, C. \& Wolf, C. M. (1953). “Geological features of the Panasqueira Tin-Tungsten ore occurrence (Portugal) “. Boletim da Sociedade Geológica de Portugal, XI (I): 1-58.

Bussink, R. (1984). "Geochemistry of the Panasqueira tungsten-tin deposit, Portugal". Geologica Ultraiectina, 33, $170 \mathrm{p}$.

Cabral, J. (1989). “An example of intraplate neotectonic activity, Vilariça Basin, northeast Portugal". Tectonics, 8: 285-303.

Cabral, J. (1995). "Neotectónica em Portugal Continental". Memórias do Instituto Geológico e Mineiro, 31: 265 p.

Carvalho, A. M. G. (2002). "Introdução ao Magmatismo e das Rochas Magméticas". Âncora Editora, 435 p.

Cavey, G. \& Gunning, D. (2006). “Updated technical report on the Panasqueira mine, Distrito de Castelo Branco“. Portugal. OREQUEST: 67 p. 
Clark, A. H. (1970). "Potassium-argon ages and regional relationships of the Panasqueira tin-tungsten mineralization". Comunicações dos Serviços Geológicos de Portugal, 54: 243-261.

Daveau, S.; Birot, P. \& Ribeiro, O. (1986). "Les bassins de Lousã et d'Arganil". Vol. I e II, Memórias do Centro de Estudos Geográficos, 8.

Dias, G.; Leterrier, J.; Mendes, A.; Simões, P. P. \& Bertrand, J. M. (1998). “U-Pb zircon and monazite geochronology of post-collisional Hercynian granitoids from the Central Iberian Zone (Northern Portugal)". Lithos, 45: 349-369.

D'Orey, F. C. (1967). "Tungsten-tin mineralization and paragenesis in the Panasqueira and Vale da Ermida Mining Districts, Portugal“. Comunicações dos Serviços Geológicos de Portugal, 52: 117-167.

Ferreira, D. B. (1981). "Carte Geomorphologique du Portugal”. Memórias do Centro de Estudos Geográficos, 6: 53 p.

Ferreira, N.; Iglesias, M.; Noronha, F.; Pereira, E.; Ribeiro, A. \& Ribeiro, M. L. (1987). "Granitoides da Zona Centro Ibérica e seu enquadramento geodinâmico". In: F. Bea, A. Carnicero, J. Gonzalo, M. Lopez Plaza, M. Rodriguez Alonso, Eds.; Geologia de los Granitoides y Rocas Asociadas del Macizo Hesperico, Editorial Rueda, Madrid. (Libro de Homenaje a L. C. García de Figuerola): 37-51.

Foxford, K. A.; Nicholson, R. \& Polya, D. A. (1991). "Textural evolution of W-Cu-Snbearing hydrothermal veins at Minas da Panasqueira, Portugal." Mineralogical Magazine, 55: 435-445.

Gonçalves, A. (2007). “Mina da Panasqueira - Contributo para um Plano De Recuperação Ambiental e Paisagística". Dissertação de Mestrado em Geografia, especialização em Geografia Física e Estudos Ambientais, apresentada à Faculdade de Letras da Universidade de Coimbra: 163 p.

Kelly, W. C. \& Rye, R. O. (1979). “Geologic, fluid inclusions and stable isotope studies of the tin-tungsten deposits of Panasqueira, Portugal". Economic Geology, 74: 1721-1822. 
Lourenço, A. (2006). “O Granito da Panasqueira (Cúpula da Barroca Grande). Estudo de um sistema granítico associado a mineralizações de estanho". VII Congresso Nacional de Geologia - Universidade de Évora: 187-190.

Lourenço, A. (2002). "Paleofluidos e mineralizações associadas às fases tardias da Orogenia Hercínica". Dissertação de Doutoramento apresentada ao Departamento de Geologia, Faculdade de Ciências da Universidade do Porto: 326 p.

Lourenço, L. (1996). "Serras de Xisto do Centro de Portugal. Contribuiç̧ão para o seu conhecimento geomorfológico e geo-ecológico". Dissertação de Doutoramento em Geografia Física apresentada à Faculdade de Letras da Universidade de Coimbra, 757 p.

Marignac, C. (1973). “Analyse estructurale de l'environment du gisement à tungstenétain de Panasqueira (Beira Baixa, Portugal); implications génétiques". $\underline{\text { C. R. Acad. Sci. }}$ Ser. D., Paris, 277: 269-272.

Marques, F.; Mateus, A. \& Tassinari, C. (2002). "The Late-Variscan fault network in central-northern Portugal (NW Iberia): a re-evaluation". Tectonophysics, 359: 255-270.

Noronha, F.; Dória, A.; Dubessy, J. \& Charoy, B. (1992). "Characterisation and timing of the different types of fluids present in the barren and ore-veins of the W-Sn deposit of Panasqueira, Central Portugal". Mineralium Deposita, 27: 72-79.

Oliveira, J. T. \& Pereira, E. (Coord.) (1992). “Carta Geológica de Portugal na Escala 1:500000". Serviços Geológicos de Portugal.

Perdigão, J. C. (1971). “O Ordovícico de Fajão, de Unhais-o-Velho, de Salgueiro do Campo e de Penha Garcia (Beira Baixa)". I Congresso Hispano-Luso-Americano de Geologia Económica, Secção I - Tomo II: 525-540.

Polya, D. (1987). "Chemical behaviour of tungsten In hydrothermal fluids and genesis of the Panasqueira W-Cu-Sn deposit, Portugal. An experimental, theoretical and field study". Tese de doutoramento, Universidade Manchester, 243p.

Rebelo, F. (1975). "Serras de Valongo. Estudo de Geomorfologia". Suplementos de Biblos, 9, Coimbra.

Reis, C. (1971). “As Minas da Panasqueira“. Boletim de Minas, 8 (1): 3-44. 
Revista Bocamina (1997). Panasqueira. Grupo Mineralogista de Madrid, Revista de Minerales y Yacimientos: $41 \mathrm{p}$.

Ribeiro, A.; Antunes, M. T.; Ferreira, M. P.; Rocha, R. B.; Soares, A. F.; Zbyszewski, G.; Almeida, F. M.; Carvalho, D. \& Monteiro, J. H. (1979). "Introduction à la Géologie Générale du Portugal”. Publicações dos Serviços Geológicos de Portugal: 114 p.

Ribeiro, A. \& Pereira, E. (1981). “Controlos paleogeográficos, petrológicos e estruturais na génese dos jazigos portugueses de estanho e volfrâmio". Geonovas, 1 (3): 23-31.

Ribeiro, A.; Kullberg, M. C.; Kullberg, J. C.; Manupella, G. \& Phipps, S. (1990). “A review of Alpine tectonics in Portugal: Foreland detachment in basement and cover rocks". Tectonophysics, 184: 357-366.

Ribeiro, A. (1988). “A Tectónica alpina em Portugal”. Geonovas, 10: 9-11.

Ribeiro, O. (1949a). "A Cova da Beira - Controvérsia de Geomorfologia". Comunicações dos Serviços Geológicos de Portugal, Tomo XXX: 4-23

Sousa, B. (1985). "Perspectiva sobre os conhecimentos actuais do Complexo XistoGrauváquico de Portugal." Mem. Not. Mus. Lab. Min. Geol. Univ. Coimbra, 100: 1-16.

Teixeira, C. (1981). "Geologia de Portugal. Vol I - Precâmbrico, Paleozóico". Fundação Calouste Gulbenkian, Lisboa, 629 p.

Thadeu, D. (1949). “A Cordilheira Central entre as Serras da Gardunha e de São-Pedrodo-Açor". Boletim da Sociedade Geológica de Portugal, VIII: 5-19.

Thadeu, D. (1951a). "Geologia do Couto Mineiro da Panasqueira". Comunicações dos Serviços Geológicos de Portugal, 32: 5-64.

Thadeu, D. (1951b). "Geologia e jazigos de chumbo e zinco da Beira Baixa”. Boletim da Sociedade Geológica de Portugal, IX: 1-145.

Thadeu, D. (1971). "Jazigo Estano-Volframítico da Panasqueira". Livro Guia da Excursão N. ${ }^{\circ} 7$ do I Congresso Hispano-Luso-Americano de Geologia Económica.

Thadeu, D. (1973). "Les gisements stanno wolframitiques du Portugal”. Ann. Soc. Géol. Belg., 79/1: 5-30. 
Thadeu, D. (1979). Le gisement stanno-wolframifère de Panasqueira (Portugal). Cronique de la Recherche Minière, 450: 35-42.

\section{Agradecimentos}

Os autores agradecem à Administração da Sojitz Beralt Tin \& Wolfram, Portugal S. A., na pessoa do Eng. ${ }^{\circ}$ Corrêa de Sá, toda a disponibilidade e colaboração prestada para a realização deste trabalho. À Dr.a Paula Ávila, pela preciosa indicação de alguns dos dados relativos à área, nomeadamente, o trabalho de cartografia que foi desenvolvido para o Projecto "e-Ecorisk", financiado pela Comissão Europeia. Também, agradecemos a dois revisores anónimos pelos comentários e sugestões. 